\title{
Urgensi Fiqih Nadzar Dalam Proses \\ Pernikahan
}

\author{
Dodi Yarli R. \\ Sekolah Tinggi Ekonomi Islam Tazkia Bogor \\ dodiyarli@gmail.com
}

\begin{abstract}
The least knowledge of figh in Islam resulted in many people who violate it. such as marriage issues. many people do not know about figh in the marriage process. So many who do wrong before marriage with courtship or free sex that is prohibited in Islamic law is prohibited.in Islamic law one of the processes in marriage is to see (nadzar) the prospective wife or husband. Seeing a potential wife or husband to be one cause to achieve happiness in the family. Prophet Muhammad advised his followers to see his future wife, so do not regret after married.
\end{abstract}

Key word: Islamic law, nadzar, married

\section{A. Pendahuluan}

Minimnya edukasi kepada remaja tentang urgensi agama dalam interaksi sosial, khususnya dalam pernikahan menjadikan banyak diantara mereka yang terjebak pada pergaulan bebas. Fakta yang terjadi saat ini, tidak sedikit para remaja yang terjerumus ke dalam Free sex, disebabkan terlalu jauhnya kebebasan mereka dalam bergaul, batasbatas pergaulan antara pria dan wanita. Mencari pasangan hidup seperti mencicipi makanan.Gonta ganti pacar sudah menjadi tradisi dan kebiasaan.Berbeda ketika mereka mengerti aturan Islam.

Islam juga tidak melarang mengenal calon pesangan.Karena mencari pasangan hiduptidak seperti membeli kucing dalam karung. Dalam syariat Islam, manusia diberi kebebasan memilih dan menyeleksi siapa saja yang akan dijadikansebagai pasangan hidup. Perlu dipahami saja, kalau salah memilih pasangan hidup, sama saja salah mencarikan guru privat buat anak-anak. Orientasi jangka panjang pernikahan untuk membentuk keluarga harmonis, sakinah, mawaddah wa rahmah. 
Islam agama yang mengakomodir keinginan manusia dalam seluruh aspeknya. Termasuk aspek cara memilih pasangan hidup. Dalam masalah perkawinan, Islam telah berbicara banyak. Dari mulai bagaimana mencari kriteria bakal calon pendamping hidup, hingga bagaimana memperlakukannya kala resmi menjadi sang penyejuk hati. Islam menuntunnya. Begitu pula Islam mengajarkan bagaimana mewujudkan sebuah pesta pernikahan yang meriah, namun tetap mendapatkan berkah dan tidak melanggar tuntunan sunnah Rasulullah shallallahu 'alaihi wa sallam, begitu pula dengan pernikahan yang sederhana namun tetap penuh dengan pesona. Islam mengajarkannya. (shalih Fauzan, tt: 2).

Sebagai sarana yang objektif dalam melakukan pengenalan dan pendekatan maka diperbolehkan nadzar.Tapi nadzar berbeda dengan pacaran.Nadzar sebagai sarana taaruf secara syar'i diperintahkan oleh Nabi Muhammad bagi pasangan yang ingin menikah.Tentu ada prosedur syar'i dalam nadzar yang mengarah pada pernikahan yang syar'I dan berkah. Tulisan ini memaparkan tentang beberapa pembahasan yaitu, apa itu nadzar?, apa dasar hukumnya?, apa urgensinya?, bagaimana prosedur nadzar yang syari?; dan bagaimana pandangan ulama dalam hal itu?

\section{B. Definisi Nadzar}

Nadzar dari aspek bahasa berasal dari kataNadzara yandzuru - nadzran, Munawir mengartikan; melihat, memandang kepada. (Ahmad Warson Munawir: 1433). Jika dipahamai dalam konteks pernikahan, nadzar adalah melihat calon pasangan hidup secara langsung untuk mengetahui wajahnya, kesuburan nya dan tinggi rendah badannya.

\section{Urgensi Fiqih Nadzar}

Pada prinsipnya setiap orang yang akan menikah memiliki idealisme dan keinginan. Naluri mencari jodoh yang berwajah tampan atau cantik, kaya, keturunan orang baik dan agamanya juga baik adalah hal wajar.Nabipun mengakui hal itu.Dalam sebuah hadits riwayat sahabat Abu Hurairah ra. Nabi bersabda:

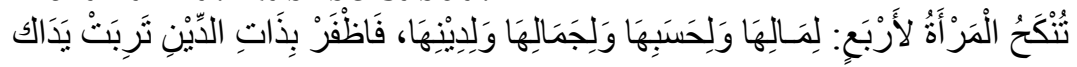

Artinya: "Wanita dinikahi karena empat perkara; karena

hartanya, keturunannya, kecantikannya, dan agamanya; 
maka pilihlah wanita yang taat beragama, niscaya engkau beruntung”. (HR. Bukhari dan Muslim)

Sebuah pernikahan yang dimulai dengan hanya mengandalkan rasa saling percaya di dalam suatu masyarakat menjadi penuh resiko di kemudian hari. Apalagi hari ini, ketika kita mudah oleng, tak teguh berpijak pada wahyu dan nurani. Beberapa halaman lewat, pada tajuk Berkelana dalam Pilihan kita sudah menyimak kisah Habibah binti Sahl yang akhirnya memilih mengajukan pisah dari suaminya, Tsabit ibn Qais. Mengapa? Habibah mengukur kekuatan dirinya yang ia rasa takkan sanggup bersabar atas kondisi suaminya yang menurutnya, "Paling hitam kulitnya, pendek tubuhnya, dan paling jelek Wajahnya". (Salim A. Fillah, https:/ /agastya.wordpress.com/2013/09/27/nadzar-taksekedar-taaruf/)

Nadzar merupakan sarana agar bisa melihat calon pasangan dengan lebih obyektif dan transparan. Nadzar juga menjadikan seseorang lebih mantap menikah bukan karena keterpaksaan apabila tetap berniat untuk menikah.Melalui nadzar bisa dilanjutkan ta'aruf sehingga masing-masing bisa mendapatkan informasi dan data secara langsung, sebagai bentuk ikhtiar untuk mempertimbangkan pengambilan keputusan.

Selain itu, nadzar bisa mempersempit peluang penyesalan setelah menikah.Dengan nadzar, setidaknya, calon pasangan telah mengenal fisiknya secara langsung, tidak hanya lewat foto atau cerita dari pihak ketiga dan diharapkan bisa merasa nyaman dengannya. Semua itu diharapkan agar penerimaan terhadap pasangan adalah penerimaan yang diiringi dengan kesadaran penuh, tidak atas dasar paksaan dari orang lain. Juga tidak layak bersandar pada asumsi.

Nadzar dalam ta'aruf juga untuk menyederhanakan masalah yang mestinya memang sederhana, tidak berbelitbelit atau rumit. Terkadang banyak yang mesti dicatat ketika taaruf dan banyak pula pertanyaan yang diajukan. Jawaban yang diinginkan pun diharapkan detail dan serbagamblang. Padahal, keberhasilan sebuah pernikahan, tidak sematamata ditentukan oleh ta'aruf yang Panjang dan lama apalagi pacaran, taaruf yang 'sederhana' bisa jadi akan membuka 
pintu-pintu yang lain yang lebih barakah, agar pernikahan islami yang diinginkanbisa diraih.

\section{Dasar Hukum Nadzar}

Ulama sepakat atas disyariatkannya nadzar. Tetapi mereka berbeda hukumnya. Mayoritas ulama dari empat mazhab secara umum cenderung kepada pendapat sunnah. Mazhab Hanafi, Maliki, Syafi'i dan sebagian ulama mazhab Hanbali sepakat bahwa hukum melihat calon istri atau suami mandub atau sunnah (Al Mausu'ah al al Fiqhiyyah al Kuwaitiyah, 19/201)

Sedangkan mazhab Hanbali secara resmi menyatakan hukumnya Mubah.Karena perintah untuk melihat diberikan setelah adanya larangan, sehingga perintah itu bukan menjadi sunnah atau wajib, melainkan menjadi kebolehan. (Al Mausu'ah al al Fiqhiyyah al Kuwaitiyah, 19/201)

Terlepas dari perbedaan pendapat statusnya hukumnya, nadzar ada tuntunan syariatnya.Banyak ditemukan dalam hadits-hadits Nabi saw. maupun pernyataan sahabat tentang disyariatkannya Nadzar. Diantaranya adalah:

1. Dari Sahabat Mughirah bin Syu'bah ra. meriwayatkan, bahwa dia pernah meminang seorang perempuan. Kemudian Nabi saw. bertanya kepadanya:

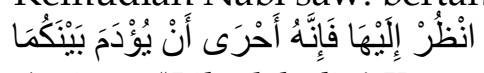

Artinya: "Lihatlah dia! Karena dengan melihatnya, itu dapat membantu untuk mengekalkan pernikahan kalian berdua"

Kemudian Mughirah pergi kepada dua orang tua perempuan tersebut, dan memberitahukan apa yang diomongkan di atas, tetapi tampaknya kedua orang tuanya itu tidak suka. Si perempuan tersebut mendengar dari dalam biliknya, kemudian ia mengatakan: Kalau Rasulullah menyuruh kamu supaya melihat aku, maka lihatlah. Kata Mughirah: Saya lantas melihatnya dan kemudian mengawininya. (HR. Ahmad, Ibnu Majah)

2. Sahabat Abu Hurairah ra. berkata,"Saya pernah di kediaman Nabi, kemudian tiba-tiba ada seorang lakilaki datang memberitahu, bahwa dia akan kawin dengan seorang perempuan dari Anshar, maka Nabi bertanya: Sudahkah kau lihat dia? Ia mengatakan: Belum! Kemudian Nabi mengatakan: "Pergilah dan lihatlah dia, 
karena dalam mata orang-orang Anshar itu ada sesuatu. (HR. Muslim)

3. Sahabat Jabir ra. Meriwayatkan bahwa Nabi saw. bersabda:

Artinya: "Apabila salah seorang di antara kamu hendak meminang seorang perempuan, kemudian dia dapat melihat sebahagian apa yang kiranya dapat menarik untuk mengawininya, maka kerjakanlah" (HR Ahmad dan Abu Daud)

\section{E. Etika Dalam Nadzar}

Disyariatkan nadzar bukan bermaksud membuka pintu kebebasan dalam melihat dan berinteraksi kepada lawan jenis.Nadzar diperbolehkan untuk memenuhihajattertentu. Seperti ketika proses khitbah, trasnsaksi jual beli, sewa menyewa, utang piutang, belajar mengajar, berobat, melayani pasien laki-laki atau perempuan untuk berrwudhu maupun istnja'. (Mausu'atul Fiqihiyah Kuwaitiyah).

Maka Islam menetapkan etika tertentu agar syariat nadzar sesuai prosedur yang telah ditetapkan.Karena asal hukumnya adalah dilarang melihat lawan jenis dan perintah untuk menundukkan pandangannya. Dalam surat an Nur ayat: 30 Allah ta'ala berfirman:

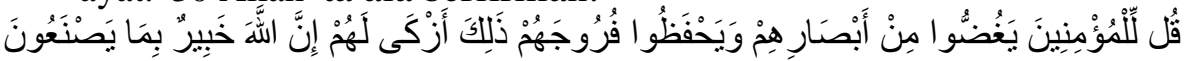

Artinya: "Katakanlah kepada orang laki-laki yang beriman: Hendaklah mereka menahan pandangannya, dan memelihara kemaluannya; yang demikian itu adalah lebih suci bagi mereka, sesungguhnya Allah Maha Mengetahui apa yang mereka perbuat" (QS An Nur: 30)

Al Mubarukfury menukil ibn Katsir dalam menjelakan ayat ini mengatakan, -Ini merupakan perintah Allah kepada hamba-hamba-Nya yang beriman agar mereka menahan pandangan dari perkara-perkara yang haram diihat. Janganlah melihat kecuali kepada hal-hal yang dibolehkan untuk dilihat dan hendaklah mereka menahan pandangan dari perkara-perkara yang haram untuk dilihat, maka hendaklah ia segera memalingkan pandangannya seperti yang diriwayatkan oleh Muslim dalam shahihnya, dari Abu Zur'ah bin Amr bin Jarir dari kakeknya, yakni Jarir bin =Abdillah Al Bajali RA, ia berkata -Aku bertanya kepada Rasulullah SAW tentang pandangan spontan. Beliau 
memerintahkanku agar segera memalingkan pandangan" (al Mubarukfuri, 2007 :823).

As sa'di memperluas perintah menundukkan pandangan mencakup aurat, wanita bukan mahram, dan remaja laki2 yang tampan yang menimbulkan fitnah, serta melihat kemewahan dunia yang bisa menimbulkan fitnah dan menggelincirkan pada yang haram. (Abdurrahman as Sa'di, 2003: 537).

Quraish Shiyab dalam menafsirkan ayat ini menyebutkan, "Wahai Nabi, katakanlah kepada orang-orang Mukmin sesuatu yang mengingatkan mereka akan perbuatan yang dapat mengarahkan kepada perzinaan dan menimbulkan tuduhan. Sesungguhnya mereka diperintahkan untuk tidak melihat sesuatu yang diharamkan, seperti aurat wanita dan anggota tubuh tempat meletakkan perhiasan pada wanita. Juga agar menjaga kemaluan mereka dengan cara menutupnya dan tidak melakukan hubungan yang dilarang. Etika seperti itu akan membuat mereka lebih terhormat, tersucikan dan terhindar dari perbuatan maksiat dan tuduhan. Sesungguhnya Allah Maha Mengetahui segala apa yang mereka lakukan dan membalas itu semua" (https://tafsirq.com/24-an-nur/ayat30\#tafsir-quraish-shihab)

Ayat diatas, berdasarkan penjelasan ulama secara tegas agar menundukkan pandangan yang diharamkan.Tapi dalam konteks tertentu seperti untuk pernikahan, maka larangan memandang yang seharusnya dihindari justru malah disyariatkan.Ada banyak dalil yang menjadi dasar masyru'iyah atas perlunya melihat calon istri atau calon suami.Diantara Etika dalam Nadzaryaitu:

\section{Tata Cara Nadzar}

Dalam Proses nadzar perlu adanya pemahaman dalam proses pelaksanaannya. Setidaknya ada tiga cara dalam proses nadzar

Pertama. Nadzar secara langsung. Dalam proses ini bisa dengan cara bersilaturrahim ke keluarga pihak wanita khususnya. Pihak wanita ditemani oleh keluarganya atau mahramnya. Sehingga dalam proses ini bisa mengetahui lebih banyak calon pasangannya dari segi fisik maupun latar belakang keluarganya. 
Sebagaimana riwayat di atas. Al Mughirah bin Syu'bah $r a$., sahabat Rasulullah yang masyhur karena kehidupan rumahtangganya yang sering dilanda prahara sejak zaman jahiliah, suatu hari ingin meminang seorang sahabiyah, seorang wanita shalihah. Maka Sang Nabi pun berkata padanya, "Lihatlah dulu kepadanya, supaya kehidupan kalian berdua kelak lebih langgeng". Kemudian Mughirah pergi kepada dua orang tua perempuan tersebut, dan memberitahukan apa yang diomongkan di atas, tetapi tampaknya kedua orang tuanya itu tidak suka. Si perempuan tersebut mendengar dari dalam biliknya, kemudian ia mengatakan: Kalau Rasulullah menyuruh kamu supaya melihat aku, maka lihatlah. Kata Mughirah: Saya lantas melihatnya dan kemudian mengawininya. (HR. Ahmad, Ibnu Majah). Ini menjadi pernikahan terakhir Al Mughirah yang lestari hingga akhir hayatnya.

Kedua. Nadzar dengan cara tidak langsung. Proses nadzar dengan cara tidak langsung adalah dengan mencari kesempatan melihatnya tanpa diketahui oleh calon pasangannya. Cara ini bisa dilakukan untuk menjaga perasan wanita khususnya, ketika dalam proses nadzar tidak ada ketertarikan dari pihak laki-laki untuk menikahinya.

Sebagian ulama berpandangan bahwa sebaiknya memang tidak diberitahu, agar benar-benar tampil alami di mata yang melihat, sehingga tidak perlu menutupi apa yang ingin ditutupi. Sebab kalau wanita itu mengetahui bahwa dirinya sedang dilihat, secara naluri dia akan berdandan sedemikian rupa untuk menutupi aib-aib yang mungkin ada pada dirinya. Maka dengan begitu, tujuan inti dari melihat malah tidak akan tercapai.

Namun mazhab Al-Malikiyah berpendapat kalau pun bukan izin dari wanita yang bersangkutan, setidaknya harus ada izin dari pihak walinya.Hal itu agar jangan sampai tiap orang merasa bebas memandang wanita mana saja dengan alasan ingin melamarnya.

Imam Ahmad meriwayatkan, bahwa sahabat Jabir menceritakan,

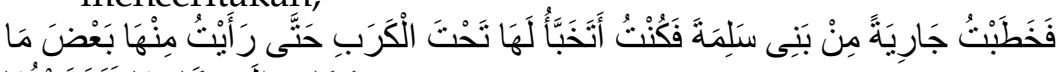

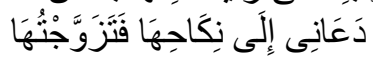


Artinya: "Aku melamar seorang gadis dari bani Salimah. Aku sembunyi-sembunyi untuk mengintipnya di balik pelepah kurma, hingga aku bisa melihat bagian anggota badannya yang membuatku tertarik untuk menikahinya.Lalu aku menikahiny" (HR. Ahmad).

Ketiga, melihat bagian tubuh yang bukan aurat kemudian mengirim utusan untuk mengetahui lebih banyak pada bagian tubuh yang menjadi aurat bagi laki-laki. Proses nadzar dalam hal ini dengan melihat bagian yang termasuk aurat untuk memastikan bahwa tidak ada cacat atau hal-hal yang sekiranya kurang disukai dengan cara mengirim utusan atau perwakilan. Calon suami bisa mengutus wanita yang menjadi mahramnya kepada calon istrinya, untuk berkenalan dan melihat langsung kondisi fisik maupun non fisiknya. Tentu karena sama-sama wanita, maka diperbolehkan melihat rambutnya, kulitnya, tubuh dan bagian-bagian lainnya.

Sahabat Anas bin Malik meriwayatkan, Rasulullah saw. pernah mengirim utusan untuk mengetahui wanita yang akan diperistrinya. Wanita yang diutus Nabi saw. adalahUmmu Sulaim dan memintanya untuk melihat dan menilai wanita yang akan dinikahinya. Nabi saw. berkata:

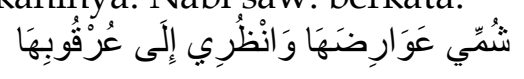

Artinya: "Ciumlah aroma mulutnya dan perhatikan 'urqubnya (tumit atau betis)" (HR. Ahmad, Thabrani, Hakim dan Baihaqi)

Melihat kerapian gigi, bau mulut, bagian leher dan keindahan betis yang ada di kedua kaki.Wanita bisa juga mengirim lelaki mahramnya untuk melihat calon suaminya.Sebab wanita tertarik pada fisik lelaki sebagaimana lelaki tertarik pada wanita. (Wahbah Zuhaili, 1985: 16)

\section{Niat dalam Nadzar}

Nadzar secara serius terhadap calon pasangan harus didasari niat untuk menikah.Apabila melihat hanya untuk mengetahui saja tanpa didasari niatan kedepan untuk menikah atau hajat-hajat darurat lainnya maka tidak dibenarkan.Mayoritas ulama dari kalangan malikiyah, syafi'iyyah dan Hanafiyah mensyaratkan dalam nadzar kaena ada keinginan menikahi calon pasangannya dan secara lahiriyah kemungkinan besar 
khitbahnya diterima, bisa menikah dengannya.Adapun Hanafiyah berpendapat, ada keinginan saja sudah cukup. (Al Mausu'ah al al Fiqhiyyah al Kuwaitiyah, 19/201)

Dalam hadits Nabi saw.disebutkan Tujuan utama dari melihat adalah adanya ketertarikan untuk menikahinya. Sahabat Abu Humaid Al-Anshari ra., Meriwayatkan dari Nabi saw., beliau bersabda:

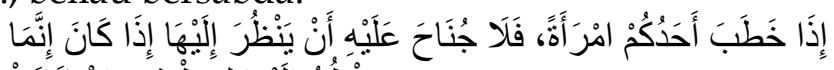

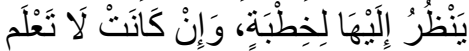

Artinya: "Apabila kalian melamar seorang wanita, tidak ada dosa baginya untuk me-nadzar-nya, jika tujuan dia melihatnya hanya untuk dipinang.Meskipun wanita itu tidak tahu"(HR. Ahmad)

Riwayat lain dari Sahabat Jabir ra. bahwa Nabi saw. bersabda:

Artinya: "Apabila salah seorang di antara kamu hendak meminang seorang perempuan, kemudian dia dapat melihat sebagian apa yang kiranya dapat menarik untuk mengawininya, maka kerjakanlah" (HR Ahmad dan Abu Daud)

\section{Nadzar Ditemani Mahram}

Disyariatkannyanadzar bukan serta merta bebas tanpa batas dan dilakukan berduaan saja, akan tetapi bagi wanita harus didampingi mahram. Tanpa kehadiran mahram dari pihak wanita, membuka pindu masuknya setan karena berduaan dengan lawat jenis yang belum halal.Hal itu tidak ada bedanya dengan pacaran yang haram hukumnya.Sahabat Jabir bin Abdullah ra. meriwayatkan dari Nabi saw.:

ومن كان يؤمن باله و اليوم الآخر فلا يخلون بامر أة ليس معها ذو محرم منها فإن ثالثهما

الثيطان

Artinya: llBarangsiapa yang beriman kepada Allah dan hari akhir maka janganlah ia berkhalwat dengan seorang wanita tanpa ada mahrom wanita tersebut, karena syaitan menjadi orang ketiga diantara mereka berdua. (HR. Ahmad)

Dalam riwayat lain, hadits Nabi saw. melarang berduaanantara laki-laki dan perempuan sebagaimana dalam riwayat Uqbah bin Amir ra.:

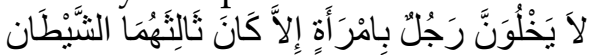

Artinya: "Tidaklah seorang laki-laki berduaan dengan seorang perempuan (yang tidak halal), karena yang ketiganya adalah setan". (HR. AtTirmizi) 
Sahabat Ibn Abbas mendengar dari Rasulullah saw.:

لا يخلون رجل بامر أة إلا مع ذي محرم فقام رجل فقال يا رسول الله امر أتي خرجت

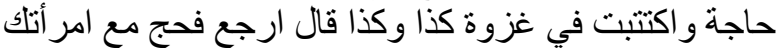

Artinya: -Dari Ibnu Abbas, bahwasanya Rasulullah shallallahu_alaihi wa sallam bersabda, -Janganlah seorang laki-laki berkhalwat dengan seorang wanita kacuali jika bersama dengan mahrom sang wanita tersebut ll. Lalu berdirilah seseorang dan berkata, -Wahai Rasulullah, istriku keluar untuk berhaji, dan aku telah mendaftarkan diriku untuk berjihad pada perang ini dan itull, maka Rasulullah shallallahu _alaihi wa sallam berkata, -Kembalilah!, dan berhajilah bersama istrimull. (HR. Bukhari Muslim)

\section{Tidak Boleh Saling Menyentuh}

Bersentuhan dengan lawan jenis yang bukan mahran hukumnya haram. Berdasarkan riwayat Ma'qil bin Yasar, bahwasanya Rasulullah saw. bersabda:

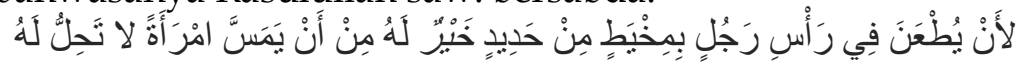
Artinya: -Sesungguhnya salah seorang diantara kalian jika ditusuk dengan jarum dari besi, itu lebih baik baginya daripada menyentuh seorang wanita yang bukan mahramnyall, (HR. Thabrani dan juga Baihaqi).

Hal itu berlaku bagi seseorang yang akan melakasanakan khitbah atau orang yang sudah khitbah dan belum terlaksananya akad nikah. Karena kedua calon pasangan belum sah menjadi suami istri.

Jumhur ulama umumnya mengharamkan sentuhan kulit antara laki-laki dan wanita yang bukan mahram, meskipun dalam rangka untuk menikahinya.

Madzhab Al-Hanafiyah, Penulis kitab Al-Hidayah berkata: "Tidak diperbolehkan bagi seorang laki-laki untuk menyentuh wajah atau telapak tangan seorang wanita walaupun ia merasa aman dari syahwatll. Penulis kitab Ad-Dur Mukhtar mengatakan: -Tidak diperbolehkan menyentuh wajah atau telapak tangan wanita walaupun ia merasa aman dari syahwat".

Madzhab Al-Malikiyah, Imam Al-Baaji berkata dalam kitabnya Al-Muntaqa, Rasulullah SAW bersabda: "Sesungguhnya aku tidak berjabat tangan dengan wanita" Yakni tidak berjabat tangan langsung dengan tangannya. Dari hal tersebut, diketahui bahwasanya cara berbaiat dengan laki-laki adalah dengan berjabat tangan 
dengannya, namun hal ini terlarang jika membaiat wanita dengan berjabat tangan secara langsung.

Madzhab As-Syafi'i Imam Nawawi berkata dalam kitabnya Al-Majmu': -Sahabat kami berkata bahwa diharamkan untuk memandang dan menyentuh wanita, jika wanita tersebut telah dewasa. Karena sesungguhnya seseorang dihalalkan untuk memandang wanita yang bukan mahramnya jika ia berniat untuk menikahinya atau dalam keadaan jual beli atau ketika ingin mengambil atau memberi sesuatu ataupun semisal dengannya. Namun tidak boleh untuk menyentuh wanita walaupun dalam keadaan demikian.

Imam Nawawi pun berkata dalam Syarah Shahih Muslim: -Hal ini menunjukkan bahwa cara membaiat wanita adalah dengan perkataan, dan hal ini juga menunjukkan, mendengar ucapan atau suara wanita yang bukan mahram adalah diperbolehkan jika ada kebutuhan, karena suara bukanlah aurat. Dan tidak boleh menyentuh secara langsung wanita yang bukan mahram jika tidak termasuk hal yang darurat, semisal seorang dokter yang menyentuh pasiennya untuk memeriksa penyakitll.

Madzhab Hambali, Ibnu Muflih dalam Al-Furu' mengatakan: "Diperbolehkan berjabat tangan antara wanita dengan wanita, laki-laki dengan laki-laki, laki-laki tua dengan wanita terhormat yang umurnya tidak muda lagi, karena jika masih muda diharamkan untuk menyentuhnya". Hal ini disebutkan dalam kitab Al-Fusul dan Ar-Ri'ayah. (Ahmad Sarwat, http:/ / www.rumahfiqih.com/x.php?id=1420891637)

\section{Nadzar terhadap bagian tertentu}

Meskipun syariat Islam mengajurkan melihat calon pasangan masing-masing, namun tetap saja ada batasan mana yang boleh dilihat dan mana yang tidak boleh dilihat.Jumhur ulama yaitu mazhab Al-Hanafiyah, AlMalikiyah dan Asy-Syafi'iyah sepakat bahwa wajah dan kedua telapak tangan hingga pergelangan tangan tidak diperbolehkan selain itu. Wajah untuk mengetahui cantik tidaknya, pergelangan tangan menunjukkan subur tidaknya. (Sayyid Sabiq, 2/30). Bagian tubuh selain keduanya tentu merupakan aurat bagi wanita, sehingga 
walaupun dengan alasan anjuran melihat calon istri, tetap saja seorang calon suami masih diharamkan untuk melihatnya. Sebab masih laki-laki ajnabi, yang kedudukan sama persis dengan laki-laki ajnabi manapun.

Berbeda dengan Dawud adz dzahairi, yang berpendapat boleh melihat seluruh tubuh. Al Aza'I boleh melihat anggota tubuh yang berdaging.Hadits-hadits yang ada tidak menunjukkan tempat tertentu untuk dilihat. Penyebutan nadzar secara mutlak bertujuan mencari bagian yang menjadi daya tarik untuk menikahinya. (Sayyid Sabiq, 2/30).

Ada riwayat dari mazhab Al-Hanafiyah yang menyebutkan bahwa kedua kaki hingga batas pergelangan atau mata kaki juga bukan termasuk aurat. (Al Mausu'ah al al Fiqhiyyah al Kuwaitiyah, 19/201)

Dan para ulama di dalam mazhab Al-Hanabilah membolehkan melihat enam anggota badan yang biasa Nampak dalam aktifitas, yaitu wajah, leher, tangan, kaki, kepala dan betis.Karena ada hajat untuk melihat semua itu. (Wahbah Zuhaili, 1985: 16)

\section{Waktu melihat}

Madzhab Syafi'I berpendapat, waktu untuk melihat calon pinangan adalah sebelum meminang, dengan diamdiam atau sembunyi tanpa sepengetahuan wanita atau kerabatnya, hal itu untuk menjaga kehormatan wanita dan keluarganya.Apabila dia tertarik maka mengajukan diri untuk melamarnya.

Madzhab Maliki berpendapat, kebolehan melihat pada wajah dan kedua telapak tangan calon istrinya sebelum akad nikah, untuk mengetahui secara pasti keadaannya dan keadaan keluarganya. Makruh melihat tanpa sepengetahuannya. Dia melihat secara langsung, atau melalui wakilnya tujuannya bukan untuk menikmati, jika tidak demikian maka tidak melihat, sebagaimana tidak boleh melihat selain wajah dan tangan. (Wahbah Zuhaili, 1985: 16)

\section{Nadzar berulang-ulang}

Boleh nadzar berulang-ulang jika dipandang perlu.Apabila melihat da nada daya tarik untuk menikah dengannya, maka sudah cukup.Haram nadzar lebih dari 
batas kecukupan untuk menikahinya.Dalam madzhab Hanbali membolehkan melihat berkali-kali untuk mengetahui kecantikannya tanpa seijinnya, dan itu lebih baik dengan syarat tidak diiringi syahwat.

\section{Tidak tertarik setelah Nadzar}

Dalam pemaparan awal sudah dijelaskan, tujuan dari nadzar adalah untuk menemukan daya tarik yang mendorong kedua pasangan agar bisa melanjutkan ke jenjang khitbah dan pernikahan. Akan tetapi apabila setelah proses nadzar tidak ada ketertarikan, maka sebaiknya dia diam saja, karena jika mengatakan -saya tidak tertarik menikahimu tentu hal itu akan menyakitkan.

Namun diperbolehkan menyebutkan alasan secara syar'I kepada orang yang diajak bermusyawarah bukan bertujuan menyakiti atau mencela, akan tetapi untuk menasehati dan mengingatkan. Rasulullah saw. bersabda tentang Muawiyah dan Abi Jahm ketika Fatimah binti Qais bertanya kepada beliau perihal keduanya yang sama-sama meminangnya. Rasulullah SAW bersabda:Adapun Abu Jahm, dia tidak meletakkan tongkatnya dari pundaknya (kiasan untuk menunjukkan sifat suka memukul), sedangkan Muawiyah sangat faqir, tidak punya harta. Nikahlah dengan Usamah bin Zaid (HR Muslim).

\section{F. Kesimpulan}

Membangun keluarga sakinah membutuhkan sebuah proses panjang. Bukan mendadak atau kebetulan. Atau melalui proses yang panjang tapi dengan cara yang salah seperti pacaran. Membangun keluarga diawali dari memilih pasangan hidup. Dan itu yang akan menjadi kunci perjalanan keluarga di masa depan. Syariat Islam memberikan kesempatan kepada manusia untuk menentukan pasangan hidup sesuai dengan idealismenya.Maka disyariatkanlah untuk nadzar dan mengenal calon pasangan secara baik dan benar.Akan tetapi dalam ta 'aruf dan nadzar, Islam juga memberikan batas-batas yang tidak boleh di langgar dalam proses pencarian jodoh ini. Semuanya etika dalam nadzar telah ditetapkan oleh syariat. 
Urgensi Fiqih Nadzar Dalam Proses Pernikahan....

\section{Daftar Pustaka}

Abdurrahman bin Nasir As Sa'di, Taisir al Karim al Rahman fi Tafsir Kalam al Mannan, Dar Ibn Hazm, Beirut, Lebanon, 2003.

Ahmad Sarwat, Bolehkah Melihat Langsung Calon Istri Dan Bagaimana

http:/ / www.rumahfiqih.com/x.php?id=142089163 7

Ahmad Warson Munawir al-Munawir, Kamus Arab Indonesia, Yogyakarta: UPBIK, t.th,

Randi $\mathrm{Mu}$, Hukum Bersalaman dengan Lawan Jenis NonMahram. Error! Hyperlink reference not valid..com/randi96/hukum-bersalaman-denganlawan-jenis-nonmahram_57f2b553d3927370168750ab

Ahmad Warson Munawir al-Munawir, Kamus Arab Indonesia, Yogyakarta: UPBIK, t.th,

https://tafsirq.com/24-an-nur/ayat-30\#tafsir-quraishshihab

Salim A. fillah, nadzar tak sekedar taaruf, https://agastya.wordpress.com/2013/09/27/nadza $r$-tak-sekedar-taaruf/

Shafiyurrahman al Mubarukfuri, al Misbah al Munir fi tahdzin tafsir ibni katsir, al Maktabah al Islamiyah, Cairo, 2007.

Wahbah Zuhaili, al Fiqh al Islam wa adillatuh, al Syamil lil adillah al syariyyah, wa al ara' al madzhabiyah, Dar al Fikr, Damascus, Suriah, 1985.

Wizaratul Auqaf wasy Syu'unil Islamiyah, Al Mausu'ah Al Fiqhiyah Al Kuwaitiyah, Darus Salasil, Kuwait, 14041427.

Sayyid Sabiq, Figh al Sunnah, Dar misr li al Thaba'ah, Kairo Mesir, tt. 